\title{
I 070 Adverse systemic right ventricular remodeling and ventricular interdependence leading to symptoms in atrial switch patients with transposition of the great vessels can be detected by biventricular geometry, function and mass assessment in CMR
}

\author{
Alban Redheuil*1, Magalie Ladouceur ${ }^{2}$, Arshid Azarine ${ }^{2}$, Laurence Iserin², \\ Daniel Sidi ${ }^{3}$ and Elie Mousseaux ${ }^{1}$
}

\begin{abstract}
Address: ${ }^{1}$ European Hospital Georges Pompidou, APHP, University of Paris Descartes and INSERM U678, Paris, France, ${ }^{2}$ European Hospital Georges Pompidou, APHP, University of Paris Descartes, Paris, France and ${ }^{3}$ Necker Hospital, APHP, University of Paris Descartes, Paris, France

* Corresponding author
\end{abstract}

from I th Annual SCMR Scientific Sessions

Los Angeles, CA, USA. I-3 February 2008

Published: 22 October 2008

Journal of Cardiovascular Magnetic Resonance 2008, I O(Suppl I):AI95 doi:I0.I I86/I532-429X-10-SI-AI95

This abstract is available from: http://jcmr-online.com/content/I0/SI/AI95

(c) 2008 Redheuil et al; licensee BioMed Central Ltd.

\section{Background}

Symptoms of heart failure are a late but strong predictor of adverse outcome in atrial switch patients. Long term adaptation of the systemic right ventricle and left ventricle is a complex process with modifications in ventricular volumes, mass, geometry and function, combined with fibrosis. These remodeling parameters need to be further investigated to guide difficult management strategies regarding medical, interventional and resynchronization therapy. In particular, we hypothesized that an adverse remodeling pattern based on geometric and functional parameters of both ventricles in atrial switch patients could be determined by CMR and differentiate symptomatic from asymptomatic patients. The subsequent study was to compare the remodeling parameters in patients to a normal population.

\section{Aim}

The aim of this study is to evaluate if the study of RV and LV volumes, mass, function and geometry can help in predicting adverse ventricular remodeling and subsequent symptoms in atrial switch patients.

\section{Methods}

Short axis cine loops and late gadolinium enhancement (LGE) studies were obtained by CMR in 31 atrial switch patients (21 asymptomatic, 10 symptomatic: NYHA>2) and 12 normal subjects. Clinical parameters, QRS duration on ECG and tricuspid regurgitation assessment in echocardiography for all patients were recorded. Indexed volumes, mass, ejection fractions, septal mass were measured in CMR. Volume, mass and volume to mass ratios were calculated for both ventricles. To assess ventricular geometry a basal CMR cine loop was selected for all subjects: perpendicular ventricular diameters (height: $D_{H}$ and width: $\mathrm{D}_{\mathrm{W}}$ ) in diastole and systole allowed to calculate distensibility indexes by subtracting ED and ES diameters in each direction. The ratio

$\mathrm{D}_{\mathrm{H}} / \mathrm{D}_{\mathrm{W}}$ defined a sphericity index summarizing ventricular shape in diastole and systole. Spherization of the ventricles during the cardiac cycle was defined as the percent difference between sphericity indexes. Systolic motion of the septum was scored as being: flat, toward the RV, toward the LV in proto systole or holo systole. LGE was classified as absent or present but focal or diffuse.

The comparison between groups for each parameter was made by ANOVA analysis. 


\section{Results}

Results are given for 3 groups: asymptomatic and symptomatic patients and controls and summarized in table 1 . Patients had lower LV and higher RV volumes and mass compared to controls and symptomatic patients had sig- nificantly higher RV mass and volumes and lower RVEF compared to asymptomatic patients. The interventricular septum had a higher mass in symptomatic patients and RV to LV mass and volume ratios were significantly higher compared to the asymptomatic group. Concerning inter-

Table I:

\begin{tabular}{|c|c|c|c|c|c|}
\hline & No symptoms & Symptoms & (p) & Controls & $(\mathrm{p})$ \\
\hline $\mathrm{n}$ & 21 & 10 & & 12 & \\
\hline Age & $25 \pm 4$ & $29 \pm 5$ & $0 / 13$ & $28.4 \pm 11$ & 0.24 \\
\hline QRS duration (ms) & $98.5 \pm 13.9$ & $128 \pm 30$ & 0.0008 & & \\
\hline Tricuspid regurgitation (mild/severe) & $4 / 0$ & $0 / 5$ & & $0 / 0$ & \\
\hline
\end{tabular}

\section{LV parameters}

\begin{tabular}{|c|c|c|c|c|c|}
\hline $\operatorname{LV} \operatorname{EDV}\left(\mathrm{ml} / \mathrm{m}^{2}\right)$ & $53.6 \pm 14$ & $51.2 \pm 13$ & 0.7 & $75.4 \pm 20$ & 0.0008 \\
\hline LV ESV $\left(\mathrm{ml} / \mathrm{m}^{2}\right)$ & $21.7 \pm 6.9$ & $25 \pm 7.7$ & 0.24 & $26.9 \pm 6.5$ & 0.12 \\
\hline LVEF \% & $58.6 \pm 12$ & $51 \pm 12$ & 0.07 & $64 \pm 4$ & 0.025 \\
\hline $\mathrm{LV}$ mass $\left(\mathrm{g} / \mathrm{m}^{2}\right)$ & $42.5 \pm 10.9$ & $49.9 \pm 13.7$ & 0.16 & $62 \pm 15.4$ & 0.0009 \\
\hline LV EDV/LV mass $(\mathrm{ml} / \mathrm{g})$ & 1.29 & 1.07 & 0.048 & 1.23 & 0.139 \\
\hline
\end{tabular}

\section{RV parameteres}

\begin{tabular}{lccccc}
\hline RV EDV $\left(\mathrm{ml} / \mathrm{m}^{2}\right)$ & $92.8 \pm 20$ & $146.7 \pm 69$ & 0.0007 & $84.9 \pm 21$ & 0.0007 \\
RV EXV $\left.\left(\mathrm{ml} / \mathrm{m}^{2}\right)\right)$ & $43.3 \pm 11.2$ & $97.7 \pm 62$ & $<0.0001$ & $36.3 \pm 7.9$ & $<0.0001$ \\
RVEF $\%$ & $53.5 \pm 6$ & $37.8 \pm 12.5$ & $<0.0001$ & $56.8 \pm 4.5$ & $<0,0001$ \\
RV mass $\left(\mathrm{g} / \mathrm{m}^{2}\right)$ & $60.2 \pm 15.7$ & $83.8 \pm 27.9$ & 0.003 & $45.7 \pm 9.2$ & $0<0.0001$ \\
RV EDV/RV mass $(\mathrm{ml} / \mathrm{g})$ & 1.59 & 1.71 & 0.4 & 1.85 & 0.136
\end{tabular}

\section{Ventricular interdependence}

\begin{tabular}{lccccc}
\hline RV mass/LV mass & 1.43 & 1.66 & 0.0005 & 0.75 & $<0.0001$ \\
RV EDV/LV EDV & 1.77 & 2.94 & 0.0001 & 1.13 & $<0.0001$ \\
IV septal mass $\left(g / \mathrm{m}^{2}\right)$ & $18.9 \pm 5$ & $23.3 \pm 6$ & 0.0397 & $22.6 \pm 5$ & 0.059 \\
RV hight Distensibility (\%) & $23.5 \pm 8.9$ & $19.5 \pm 8.8$ & 0.2 & $16.2 \pm 6$ & 0.05 \\
RV width Distensibility (\%) & $19.7 \pm 10.3$ & $11.6 \pm 12$ & 0.05 & $27 \pm 12.5$ & 0.01 \\
LV height Distensibility (\%) & $19 \pm 9.8$ & $15.8 \pm 6.3$ & 0.3 & $37.4 \pm 6.3$ & $<0.0001$ \\
LV width Distensibility (\%) & $28 \pm 16$ & $21.4 \pm 16$ & 0.2 & $31.6 \pm 6.5$ & 0.24 \\
LV sphericity index diastole & 2.27 & 2.78 & 0.01 & 1.27 & $<0.0001$ \\
LV sphericity index systole & 2.6 & 2.99 & 0.05 & 1.17 & $<0.0001$ \\
Change LV sphericity (\%) & $-16 \pm 21$ & $-11 \pm 22$ & 0.5 & $7.7 \pm 13$ & 0.0069 \\
RV sphericity index diastole & $1 / 75$ & 1.54 & 0.1 & 2.12 & 0.0006 \\
RV sphericity index systole & 1.66 & 1.40 & 0.03 & 2.45 & $<0.0001$ \\
Change RV sphericity (\%) & $3 \pm 16$ & $8 \pm 12$ & 0.4 & $-17 \pm 14$ & 0.0004 \\
\end{tabular}

Septal movement direction

\begin{tabular}{lcccc}
\hline Toward RV & 2 & 0 & 7 & 5 \\
Flat & 0 & 0 & 0 & 0.0001 \\
Toward LV holosystolic & 6 & 7 & 0 \\
Toward LV protosystolic & 13 & 3 & \\
\hline
\end{tabular}

\section{Delayed enhancement (LGE)}

\begin{tabular}{lcccc}
\hline Absent & 12 & 2 & 0 & $<0.0001$ \\
Present: focal & 7 & 1 & 0 & 0 \\
Present: diffuse & 2 & 7 & 0
\end{tabular}


ventricular dependance and remodeling: RV distensibility indexes were lower for the patients compared to controls and significantly lowest for the symptomatic group. Sphericity indexes showed that the systemic RV of symptomatic patients was "rounder" in shape in diastole and systole than the asymptomatic patients. The LV of asymptomatic patients had a similar pattern than the normal RV of controls (triangular shape becoming elongated in systole) whereas the LV of symptomatic patients is even more elongated. The symptomatic patients have a higher rate of inversed septal motion toward the LV (concave) in holo systole and a higher rate of LGE, particularly diffuse LGE compared to the asymptomatic group. Severe tricuspid regurgitation was present in 5 out of 10 symptomatic and in no asymptomatic patient.

\section{Conclusion}

The remodeling pattern of the systemic RV of symptomatic atrial switch patients determined in CMR by volume, mass and simple geometry indexes is marked by notable RV and septal hypertrophy, RV dilatation and holosystolic septal inversion with increased ventricular interdependance potentially explaining its spheric and dilated shape with low distensibility and a higher rate of tricuspid regurgitation and fibrosis.

Publish with Bio Med Central and every scientist can read your work free of charge

"BioMed Central will be the most significant development for disseminating the results of biomedical research in our lifetime. " Sir Paul Nurse, Cancer Research UK

Your research papers will be:

- available free of charge to the entire biomedical community

- peer reviewed and published immediately upon acceptance

- cited in PubMed and archived on PubMed Central

- yours - you keep the copyright

Submit your manuscript here:

http://www.biomedcentral.com/info/publishing_adv.asp 